\title{
Creativity at work and sustainable product development: practitioner perspectives from the clothing industry
}

\author{
Helen Goworek*, Lynn Oxborrow **, Angharad McLaren **, Stella Claxton**, Tim Cooper **, \\ and Helen Hill ** \\ *University of Leicester \\ ${ }^{* *}$ Nottingham Trent University
}

\begin{abstract}
This chapter addresses creativity in the context of product development within the creative industries, incorporating an example from the clothing industry. In relation to creativity and product development, designers are supported by many other actors, such as technologists, engineers and buyers, who are also creative in their own right. We begin by exploring creativity at work, which we consider to encompass idea generation comprising creative problem-solving, moving beyond product ideas to service and commercial concepts. Product (or service) development, improvement and practical process adaptation are amongst the various tangible aspects of creativity which can be managed, whereas other aspects of creativity such as creative thought processes are less tangible and consequently less manageable. In the clothing sector the temporal, financial and technical parameters of creativity at work are set for designers by other functions within their own organisation and from their clients and suppliers, subject to conflicting commercial demands. Sustainable design through clothing longevity appears at odds with the priorities of the prevailing 'fast fashion' business model. Challenging issues such as sustainability and longevity require innovative solutions and the creative thought processes used by designers could be central to improving sustainability within the fashion industry.
\end{abstract}


To demonstrate how creativity at work can operate in practice, we present a case that investigates the implementation of creative idea generation, within the boundaries of sustainable product development in the context of the clothing industry. This research aimed to reveal barriers, enablers, knowledge, processes, infrastructure and consumer views that support wider adoption of practices that can facilitate product longevity. We adopted a mixed methodology, including semi-structured interviews and round-table discussions with garment industry stakeholders from a range of roles in fashion retail, the supply chain and academia, to debate specific themes concerned with supplying clothing that lasts for longer. Subsequently, pilot interventions highlighted the factors that, in practice, promote and inhibit improved clothing longevity.

\section{Introduction}

This chapter addresses creativity which is conceptual and practical in the context of product development, incorporating a case focusing on practice which is both creative and environmentally sustainable. Although there is the potential for creativity at work in organisations in any sector, it is clearly especially significant within the creative industries. Additionally, this is a significant field to investigate, since the creative industries sector is a major contributor to the economy, with Gross Value Added of $£ 84.1$ bn in 2014 , which has increased each year since 1997, and there are around 2.8 million jobs in the UK creative economy, of which less than half were in non-creative sector companies, according to the Inter-Departmental Business Register (DCMS 2016). However, the final figure could be larger in relation to the fashion business, since fashion design is included in this definition but fashion manufacture and retail are not.

In relation to creativity and product innovation, designers may often be automatically perceived by consumers as the central, or even the only creative actors, yet there are many other roles, such as technologists, engineers and buyers, who facilitate the creativity of designers in the workplace and who are also creative in their own right (Goworek 2006). 
However, practitioners in these supporting or parallel roles may be less likely to express their creativity aesthetically, which could explain why their creative input is less evident or not visible to consumers. Our chapter begins by exploring literature on creativity at work, before discussing how creativity can be applied to product development within the clothing industry. Lastly, we discuss how creative knowledge, skills and processes can be put into practice in a case on sustainable product development that requires both creativity and innovation, incorporating industry perspectives. The research in the case set out to reveal barriers, enablers, knowledge, processes, infrastructure and consumer views that support wider adoption of practices to facilitate product longevity.

\section{Creativity in the context of work}

The definition of creativity is a matter of some debate in terms of its scope. Certain authors consider creativity to be limited to the generation of novel ideas (Mumford and Gustafson 1988; Cox 2005; Eubanks et al. 2014), which suggests there is a level of uncertainty or risk attached, and others specify that additionally, such ideas must be useful or actionable (Berman and Kim 2010; Baer 2012; Runco and Jaeger 2012). Furthermore, creativity may be perceived by some to be restricted to particularly talented, creative individuals in artistic or cultural fields (Wilson 2009; Eubanks et al. 2014). Creativity can be considered to involve the generation of ideas that diverge from the norm and yet actors within the creative process also need to confine those ideas within limits set by society and organisations (Puryear 2014). The challenges of defining creativity (and its metaphors such as incubation and divergence) have been explored by McKerracher (2016), who questions the need to arrive at an individual definition, proposing instead to celebrate its diversity. Furthermore, there is no clear consensus on the boundaries within which creativity is located, in that idea implementation may be included or viewed as a separate subsequent stage. Baer (2012) suggests that innovation is a broader concept, comprising both creativity and implementation 
of the ideas which it generates. This would seem a reasonable assumption, since many more creative ideas are likely to be generated than are put into practice (Sohn and Jung 2010).

Berman and Kim (2010: 621) are amongst the authors who agree that innovation is broader than creativity: "innovation is commonly defined as the process whereby new ideas, objects, or practices are created, developed, implemented, and diffused (e.g., Rogers 1995; Walker 2006)". Rogers (1997:8) concurs, also believing that idea generation is narrower than innovation, since he describes innovation as "the process of converting preferred ideas into real products", adding that curiosity and humour are important factors in creativity, of which all people are capable to differing extents. However, Puryear (2014) criticises the study of creativity for focussing on idea generation and its end results whilst neglecting the cognitive processing that occurs in the interim, which is a strong potential area for future study in the creative sector. Taking the various views in the literature into account, within this chapter we consider creativity to encompass idea generation which comprises creative problem-solving, moving beyond product ideas to includee service and commercial concepts, with functional as well as artistic and aesthetic considerations.

\section{Managing Creativity}

Product (or service) development, improvement and practical process adaptation are amongst the various tangible aspects of creativity which can be managed. Other aspects of creativity such as creative thought processes are less tangible and can consequently be somewhat difficult to manage, particularly as those responsible for managing creativity can have different perspectives and motivations from those who are tasked with creating new ideas (Eubanks et al. 2014). Furthermore, creative ideas may not necessarily seem logical (Puryear 2014) and may thus be incompatible with the more logical framework expected by highly business-orientated employees. Risks inherent in the novelty of creative ideas may 
incite conflict between different teams within an organisation, leading to disagreement around which concepts should be selected or limiting the effectiveness of their implementation (Frost and Egri 1991; Green, Welsh, and Dehler 2003; Baer 2012). This can result in organisations selecting ideas which inhibit creativity, in that they are less of a departure from the norm and are therefore considered a safer option. Employees whose roles are finance-orientated may be more prone to selecting risk-averse creative ideas, despite the fact that the increased risk in more creative proposals also offers the potential for increased profitability by producing original goods and services that could consequently gain a competitive advantage. However, measuring levels of creativity can be problematic, since the number of ideas generated may not relate directly to the critical or commercial success of a product or service (McMahon et al. 2016). Even with a high rate of idea generation, the concepts which are implemented could have been amongst those which were devised earliest, thus adding complexity to the task of measuring creativity.

Isaksen et al. (2014) investigated the personality factors behind creative problem-solving styles, since creativity is usually essential in order for organisations to remain competitive, and to gain insights into people's approaches to creative problems which can help to establish suitable conditions to encourage creative outputs. Problem-solving styles may require adaptation in order to incorporate sustainable thinking. 'Creative style' refers to the ways in which people express or apply creativity (Treffinger et al. 2008). Management instruments can be utilised to evaluate creative styles, including FourSight, which can assess attitudes towards the stages of creative problem-solving, categorising employees as Clarifiers, Ideators, Developers or Implementers, a system used in practice by organisations including Google, IBM and 3M (Foursightonline 2017). Creative thinkers have also been classified into two categories by Kirton (1976): Adaptors, who follow rules and develop solutions within existing teams and structures and Innovators, who are less disciplined, yet promote change by approaching tasks from novel perspectives, moving beyond a problem's boundaries. The Innovator approach is more typical of designers who wish to push the 
boundaries of product development and create a sense of freedom in their work. In practice, both innovative and developmental approaches can be contributed by different team members or by an individual who has a combination of both. Generating ideas which are perceived by others as being highly creative can be driven by the creator's desire to be original and may even be part of an evolutionary drive to innovate (Perkins 1984; Abra 1997; Puryear 2014).

Research suggests that creativity can be enhanced when teams perceive that it is expected of them and when they work together supportively with shared goals and relevant networks (Gilson and Shalley 2004; Eubanks et al. 2014). Encouraging an environment which fosters teamwork, through aspects such as more effective workplace location and initiating meetings, can be relatively easy and economical for managers to implement (Rogers 1997), which can lead to enhanced creativity. Eubanks et al. (2014:223) found that a positive relationship with the team network and autonomy made employees more willing to be creative:

The freedom to try new things plays a vital role for employees engaging in creative endeavors. This freedom can be influenced by one's relationship with her supervisor, relationship with her team, and various work pressures. One of the first steps to reaching creative output is to have a playful attitude toward work where there is encouragement and processes that allow individuals to take risks and try new things...

Similarly, branding consultant Martin Knox (2017) describes the importance of being able to make mistakes without risk whilst creating concepts, so that employees are encouraged by their companies to be creative in their ideas. The concept of Creativity Management has been developed with the aim of increasing the volume of novel ideas which can be implemented within organisations by fostering an environment that encourages staff to propose innovative ideas via training or brainstorming, motivated by incentives and striking a balance between top-down and grassroots innovation. Creativity Management enables 
managers to then select which ideas to progress to the implementation stage (Berman and Kim 2010).

\section{Creativity in education and industry for creative fashion roles}

Individual approaches to work in creative roles are often inspired by the actors' educational background and product developers usually require relevant specialist education in order to learn the design and/or technical skills related to their work. Academics in all disciplines can be considered to implement creative processes within their work, for example through curriculum development for new courses or individual lectures, which can offer the opportunity to insert contemporary issues which require creative solutions within this content, such as minimising sustainability impacts. However, in disciplines which are overtly labelled 'creative', for example in a University's School of Art and Design, there is clearly a large amount of creative work being implemented and creative academic research represents a knowledge base which can have unrealised potential for commercialisation (Mould et al. 2009). Of all the creative curriculum, fashion is generally perceived to be a highly creative and innovative subject. Clark (2009) categorised 'designer fashion' as one of the creative industries in the UK (although the definition of 'designer fashion' is not clear, since all fashion products need to be designed) and found that the fashion business was considered to be part of the 'experience economy' in Denmark and Sweden. A clearer definition of the creative industries is called for (ibid.), although the somewhat intangible and fluctuating nature of this sector makes its categorisation problematic.

Interdisciplinary work can provide wider opportunities for educators in disciplines connected to the creative industries, and has been implemented by the team in this chapter's case. Collaboration between business schools and creative fields has been encouraged by organisations such as the Design Council to ensure that managers gain more understanding 
of creativity and that equally, creative roles have an appreciation of business, building stronger links and the sharing of skill-sets between business schools and creative disciplines in recent years, reflecting the way that industry has to work. Wilson (2009:188) therefore states:

What is needed is a fundamental review of the behaviours, knowledge and skills that successful creatives and managers actually exhibit, and of the particular contexts in which they interact. To this end, there is an opportunity here too for researchers (from different disciplines and working in separate schools and faculties) to work together on truly inter-disciplinary research projects.

Our chapter's case explores fashion product development and fashion design is usually viewed automatically as the central (and sometimes only) creative role in the clothing industry. However, there are many other parallel or supporting roles that are also creative and which facilitate the creativity of the design team. Garment- or textile-technologists (usually working for manufacturers/suppliers), buyers and merchandisers (from clothing retailers) also have parts to play in both enabling and directing designers' creativity (Goworek 2006), as well as senior managers responsible for creative strategy and process innovations. Although technologists can place constraints on design due to ensuring that product features are viable in production from a technical perspective, they could also be considered to be guiding the designers more effectively towards practical design solutions. For example, such constraints could include restricting the use of incompatible fabrics or dyes which are not colour-fast, thus avoiding seams ripping or dye transferring onto furniture after consumers purchase the garments.

Retail buyers set further creative parameters in terms of briefing designers to achieve target prices for garments, to appeal to consumers' tastes and to achieve this within a specific timescale, all of which may limit the use of components and design features. Therefore, in the clothing sector the temporal, financial and technical parameters of creativity at work are set for designers by technologists, buyers and merchandisers within their own organisation 
and from their clients and suppliers. Research indicates that individuals or collaborative groups can be equally creative, with groups being particularly effective at making ideas marketable (McMahon et al. 2016) and this relates to the way in which the fashion business operates, with designers tending to work individually on design concepts at the idea generation stage, after a briefing by other team members or clients, followed by team work on the commercialisation of selected ideas. It is also important to note that the fashion and textiles business can exist on many scales and those responsible for creating ideas may automatically be in charge of financial aspects. For example, in Gale and Kaur's (2002) book about textiles, the section on 'The Creative' incorporates chapters not only on the textile designer and textile artist, but also the craftsperson and designer-maker, who may operate as sole traders or freelancers taking on virtually all management functions.

\section{Environmentally Sustainable Fashion Product Development}

Designing is a creative problem-solving role, described by Walker (2009:35) as "an activity that is inherently concerned with divergent problems - problems that have no definitive solution. Instead, during the creative design process a range of factors become synthesized". Design is also a contemplative activity, requiring periods of deep thinking on an individual basis for designers to create product concepts, interspersed with collaborative discussions with colleagues about creative and practical issues. Fashion design may be perceived as one of the ultimate creative endeavours; developing spontaneous innovations through a magical combination of flair and flourish. In practice however, the process can be somewhat formulaic, largely consisting of rendering various permutations of colour, componentry, construction, fastenings, fabric, finish, length, width, seams and silhouette (Goworek 2006). Moving beyond these functional and aesthetic considerations, designers can benefit from understanding of business operations by working in concert with other functions within an organisation and externally. Aiming to make products more sustainable is an additional constraint and challenge for designers to address within the product development process. Consideration of negative sustainability impacts of clothing is 
essential in a society which produces increasingly high levels of textile waste (Hjelmgrem et al. 2015). Sustainable product design aims to minimise or remove such negative sustainability impacts on the environment and society. For example, negative impacts can be reduced by the selection of more environmentally or socially sustainable materials and components or production processes, with consideration for future re-use or sustainable disposal.

Cucuzzella (2016) points out that sustainability can be either an obstacle or lever for creativity, since it can result in a restrictive design brief or one that is open to new concepts, and she questions where creativity fits within sustainable design, offering Life Cycle Analysis (LCA) and Ecological Footprint as examples of purposeful tools that designers can use to evaluate their designs, with a positive, preventative approach. Grose (2013) takes LCA into account by describing making garments more sustainable or durable as 'misplaced strategies' unless their ultimate use is also considered. Quality is also of importance to provide consumers with longevity and durability in their clothing (Streit and Davies 2013) and the relationship between price, purpose, fashionability and longevity through astute fabric and styling decisions during product development can lessen clothing's negative sustainability impacts (Goworek et al. 2013). Fletcher and Grose (2012:9) "favour a multifarious approach to sustainability in fashion, working both inside and outside the sector and across all parts of the economy" and they foresee designers becoming more informed, with a new vocabulary and ways of thinking that could enable them to achieve new levels of innovation, such as the perpetual recycling of fibres, spurred on by government policies and new industry standards. Some would question whether creativity plays a part in design interventions for sustainability and in response, Cucuzzella (2016:1548) points out that:

Regardless if the perspective for exploring alternatives of unsustainable situations is short, medium or long-term, designers as producers of culture strive for creative outcomes in all their projects. Design has become an increasingly important medium for understanding and addressing the current environmental and social crisis. As a vehicle for change, with the intent of improving a given situation into a better one 
(Simon, 1969), design can therefore contribute to the changes necessary such that society can move towards a type of development that is sustainable (Fletcher et al., 2001).

Multi-disciplinary co-operation between actors across the product lifecycle (design and production teams; buyers; suppliers; marketing and corporate responsibility managers) helps achieve simultaneous customer value and sustainable design (Hong 2009; Curwen et al. 2012). In turn, company ethos, systems-thinking (Hong 2009) and a pro-active business culture support sustainable design objectives, structure and processes (Curwen et al. 2012). The integration of suppliers and cross-functional teams collectively address principles of design for sustainable clothing: company mandate, shared values, knowledge-sharing, reorganisation and supply chain simplification (ibid.) and help to optimise materials, design and consumption (Gam et al. 2008). Reducing sustainability impacts by maintaining longer active use of clothing requires a pro-active, visionary design approach (Laitala and Klepp 2011; Niinimäki 2012) to maximise emotional durability. Sustainable fashion design literature proposes that designers are appropriately informed and able to influence the product development process (Fletcher 2007; Fletcher and Grose 2012; Gwilt and Rissanen 2010; Black 2008). However, Palomo-Lovinski and Hahn (2014) suggest that designers working for mainstream fashion businesses lack the empowerment and awareness or knowledge required to influence the process. Meanwhile, conflicting commercial demands compel clothing retailers to reduce costs or maintain brand integrity through product aesthetics, quality, functionality and availability (Brun and Castelli 2008). Sustainable design through clothing longevity appears at odds with the cost and time priorities of this prevailing fashion business model (Cooper et al. 2013) in which only small firms have been able to do more than adopt incremental product and process improvements and reshape their whole supply chain (Caniato et al. 2012). Eubanks et al. (2014:233) propose that "variables such as positive peer group, positive interpersonal exchange, intellectual stimulation, and participation indicate the importance of the team to engage in creative endeavors". 
Therefore, a team focusing on sustainable garment design can be encouraged to thrive in a working environment that supports these elements.

Creativity can in itself be a challenge to durability in relation to fashion, alongside identity formation and communication via clothing, due to their resource-intensive nature (Fletcher 2012). Challenging issues such as sustainability and longevity require innovative solutions and the creative thought processes used by designers could be central to improving sustainability within the fashion industry. Moving beyond the product development phase, companies can implement take-back schemes which oblige them to accept returned garments after consumer usage for reuse, re-manufacture or disposal to save them from landfill. This accountability can thus give clothing brands a different, more sustainable perspective on design, production and distribution, with "a growing body of designers who fuse thrift with creativity and embellishment" according to Fletcher and Grose (2012:67). Conversely, consumers' lack of empathy with basic fashion products, in combination with low prices and accessibility, can result in garments' disposal prior to becoming worn out and this absence of an emotional connection between the consumer and the product can lead to premature disposal in landfill, where physical durability becomes problematic (ibid.).

Government policy can make a rapid and direct impact upon consumer behaviour by making people purchase or dispose of products in a more sustainable manner (e.g. making it compulsory for retailers to charge for carrier bags has led to a significant reduction in their consumption) and government-funded research, such as the project in our case below, can be structured to influence designers to apply the outcomes to their creative practice, thus also helping consumers to change their behaviour.

Whilst it is debatable whether or not brainstorming in teams is more effective than developing ideas individually (McMahon et al. 2016), our empirical experience in the fashion business and research projects tell us that working as a team with representatives from different functions is essential in fashion product development, to provide input from 
aesthetic, technical and commercial perspectives which ensure that technical feasible garments with market appeal can be produced effectively. Accordingly, Fletcher and Grose (2012:181) predict that creative roles will work together more effectively in the near future: "designers will become strategists and comfortably work alongside economists, policymakers, ecologists, business leaders and scientists, working collaboratively to influence positive societal and cultural change".

Adding sustainability to the more established list of design constraints, such as price, technical considerations and aesthetic appeal to consumers, could however be considered to potentially make the design role somewhat frustrating and inhibit creativity. Despite this, sustainable design has proven to be a popular topic for innovative students and academics during the last two decades, as evidenced by the establishment of professorships and courses in this field at Universities known primarily for their creative approaches, such as University of the Arts subsidiaries London College of Fashion and Central Saint Martins. To encourage creative and sustainable product development, Niinimäki and Hassi (2011) propose a range of design strategies for sustainable fashion such as co-design, customisation, personalisation and modular DIY kits and explore consumer responses. In addition to such strategies, consumer creativity could help customers to form more of an emotional attachment to clothing items when they have engaged with the product development process and may also have paid a higher price for a certain level of customisation. Consumers can also be creative through repairing items (McLaren and McLauchlan 2015) using craft skills which adopt the same techniques that others implement within their paid employment. There is a sense that when creativity of this kind provides people with such satisfaction and enjoyment that they choose to do it voluntarily, virtually identical processes can move beyond the realm of work to become creative pastimes.

\section{Drivers for Longer Clothing Lifetimes}


Extending product lifetimes encompasses improvements to physical durability, the behaviour of consumers in their purchase, care and disposal of products and wider socio-cultural influences (Cooper 2010). Since one third of the UK population say they would buy clothing made to last longer (WRAP 2013) it is not unreasonable to assume that it should be possible to increase the average life expectancy of clothing items by around one third (WRAP 2012), in which case the environmental footprint of clothing could be reduced by $20 \%$. However, while developing longer-lasting clothing is technically achievable (WRAP 2014) many businesses have failed to adopt this strategy because the commercial case for doing so is yet to be proven. Fast fashion, with prolific new style turnaround, short-lived fashions and low costs, remains one of the prevailing models, particularly within the lower-priced level of the UK mass market. However, the values of other consumers, who prioritise sustainability over price (Mintel Oxygen 2011; WRAP 2012) increase the opportunity for longer-lasting classic items and better processes for clothing recycling and re-use in some markets (WRAP 2012). It is also recognised that clothing can defy obsolescence unintentionally, rather than through design planning or the features of a product, evidenced by ethnographic research that demonstrates consumers' ability to extend the life of clothing through thoughtful usage (Fletcher 2012).

The clothing industry itself offers numerous challenges to adopting more sustainable practices. It is accepted that most clothing retailers and brands have global supply chains, (Spicer 2006), and that most large clothing businesses operate in similar ways, adopting established 'norms' (Giddens 1986). In this context, agency, defined by Barker (2005:448) as the "capacity of individuals to act independently and make their own choices", is limited and there are few disruptive influences. However, research into sustainability management suggests that the governance structures of some firms need disrupting to enhance the agency of designers and creative roles. This in turn would help to create more sustainable approaches to the product-service mix (Hoejmose et al. 2012; Lockett et al. 2011); the processes that support re-use and recycling (Bostrom et al. 2015; Hoejmose et al. 2012; 
Lozano et al. 2015); and the concept of 'use' (Taylor 2013). The 'agency of design' is discussed in creating sustainable fashion products by Farrer (2010:22), although the multidisciplinary nature of the commercial product development process, which extends beyond the design function, can often be overlooked.

\section{An example of Creativity at Work in action: The case of clothing longevity}

To demonstrate how creativity at work can operate in practice, here we present a case which investigates the implementation of creative idea generation, within the boundaries of sustainable product development in the context of the clothing industry. In the UK, government sustainability policy supports initiatives aimed at reducing the disposal of excessive amounts of clothing to landfill (Defra 2011). One such initiative is developing and selling clothes that lasts for longer. This policy assumes that new business models increase the commercial viability of such a strategy to retailers and brands (WRAP 2012). However, industry strategists remain sceptical of the commercial opportunity to increase clothing lifetimes. Our case highlights the conflicting priorities of achieving sustainability within a commercial context. It explores the roles of product development teams and the opportunity for creative solutions - not just to product design - but also to designing new service offers, new systems for re-use and recycling and new ways to commercialise and communicate a more sustainable approach to fashion. The case also examines whether traditional fashion industry structures and norms limit the agency of designers to contribute to the creation of a more sustainable future. This case examines environmentally sustainable, industry- led strategies aimed at enhancing clothing lifetimes, based largely around new product development (NPD).

Our exploration into the adoption of clothing longevity builds on a series of earlier studies, by the project team and other researchers, to establish whether it is possible to design and 
manufacture clothing that lasts for longer than average. The study utilised mixed methods, including semi-structured interviews with 25 garment industry stakeholders from across a range of roles in fashion retail and the supply chain. We subsequently conducted four roundtable discussions, engaging some 40 multi-disciplinary academic and industry experts to debate specific themes concerned with making and selling clothing that lasts for longer. In parallel, we facilitated four focus groups with representatives from various market segments to discuss their behaviours when buying, caring for and discarding clothing. Subsequently, four pilot interventions highlighted the factors that, in practice, promote and inhibit improved clothing longevity. The research was conducted by an interdisciplinary team of design and business academics, as part of a project funded by the UK Government's Department for Environment, Food and Rural Affairs (Defra) to explore how the new product development process and supply chain could extend clothing lifetimes (Cooper et al. 2016).

\section{Findings}

While generic approaches to sustainability, such as raw material impacts, energy efficiency and ethical compliance, are increasingly important to retailers and brands, to many such organisations, clothing longevity has not become a priority, since extending the longevity of garments challenges other commercial objectives, including profit margins and future sales. Challenges within the NPD process: globalisation, fast style turnover, product proliferation and the over-riding cost imperative mean that designers may be constrained, as mentioned above, and often lack control of upstream processes such as material choices and manufacturing methods. While supplier firms consistently refer to their significant skills and accumulated knowledge, they also perceive a knowledge shortfall in retail buying teams, even though it is the latter who generally drive the NPD process. This situation is exacerbated because distrust and lack of transparency between large retailers and their suppliers can mean that suppliers perceive their creative knowledge to be under-valued. Smaller, innovative retailers and brands admit that they lack sufficient power and influence 
to have any lasting impact on the practices of their suppliers, who favour larger customers. As a result, durability standards are disregarded or are of limited, short-term benefit. Furthermore, certain retailers and brands maintain that consumers undermine clothing longevity through inadequate clothing care.

Some respondents acknowledge that durability enhances brand value, regardless of its contribution to sustainability. For example, in our study a representative from a large clothing retailer stated: "if there are ways and means of making longer lasting garments, better quality garments commercially effectively then that's what we should be doing anyway". Meanwhile, some small brands have begun to offer more service-oriented solutions, such as repair and alterations, whereas others are taking a creative approach by designing modular or more adaptable clothing, which is multi-functional. All extend the life of clothing and can provide alternative revenue streams. Such solutions to enhancing durability need to be 'designed-in' requiring a strategic steer, multi-disciplinary creative approach that spans functional boundaries, and the freedom to apply technological know-how. Solutions to problems such as colour fading, pilling and failed trims, were frequently to make alternative choices, not to make improvements to the failed elements. According to one of the retailers we interviewed, this involves "working far enough in advance of the production to pick up any problems and resolve them ... as early in the process as possible". Within this retailer's NPD team, "the buying, the designing and the technology and merchandise are all on the same level (office) and we all go on trips .... we're all in the developing meetings together." This supports multi-faceted approaches to creativity and the importance of early design involvement. Consequently, collaboration between relevant creative roles from the initial stages and consideration of time-planning are two of the factors that facilitate sustainable product development.

In one supplier company in our sample, the design team was fragmented between a small UK team close to the customer and a technical team located in China, close to production. 
The teams worked closely together, although not without problems, and the structure enabled collaboration with the customer about design and between the technical team and suppliers. Engineering products to meet price points and deadlines were challenges to creativity and durability. A quality brand suggested that making longer lasting products would require "an investment in training and product development", as well as innovative approaches to product tests that represent wear and tear. The testing process itself also supports tacit knowledge of the product and its durability characteristics, which builds up with time and experience for designers and their colleagues in other functions. In contrast, a fabric manufacturer admitted to "experiencing mixed messages coming from the design and production departments of (its) clients, with design selecting fabrics even though production have dismissed them in the past, and production then wanting developments/modifications to be made based on test results." Using fabrics for unintended purposes can also compromise durability, as not all are made for persistent use or care, and this therefore needs to be taken into account when making creative decisions during NPD.

\section{Discussion}

These findings confirm that design for clothing longevity is constrained by traditional structures which limit the agency of some actors, particularly suppliers, to fully utilise their creative skills and knowledge within effective multi-disciplinary teams (Palomo-Lovinski and Hahn 2014). Furthermore, there is a perceived lack of respect for the creative and technical knowledge and skills found within the supply chain that constrains the drive for retailers' or brands' design teams to acquire technical knowledge. This is reinforced by inherent strategic values which favour private gain over creativity and the prevailing commercial drive to prioritise cost-savings (Hoejmose et al. 2012). The lack of agency is associated with a high level mandate to support sustainability (Curwen et al. 2012), that is not translated at commercial or operational level into clothing longevity as advocated by policy (Defra 2011). 
Where design for durability is adopted this generally supports brand values such as quality (Brun and Castelli 2008), rather than sustainability per se. Signs of a commercial case for clothing longevity are not driving change on any scale and there is a lack of enquiry in this field, whether in the agency of design (Farrer 2010), understanding of use (Taylor 2013) or generation of new business models. Contextually, the scale of accumulation and flow of capital has changed from district or national to global (Spicer 2006), while governance structures remain rooted in the West. In turn this appears to have created a fragmentation of the inter-organisational and multi-disciplinary discourse that could lead to enduring sustainability improvements from inter-firm to intra-firm level. This divergence, or hybrid organisational logic (ibid.), inhibits the discourse that could commercialise design for clothing longevity, limiting its scale to relatively small organisations and niche markets. However, the outputs of this research project offer an example of how policy has the potential to implement and accelerate change, via the publication of a report and toolkit to demonstrate strategies for incorporating durability into clothing in practice, which can inspire more sustainable creativity within fashion product development (Cooper et al. 2106).

\section{Conclusion}

The literature and the case in this chapter demonstrate that creative knowledge, skills and processes can be used at work in collaborative cross-disciplinary teams (Mould 2008) to implement sustainable product development effectively. Since creativity at work within the fashion business is not limited to the designer's role, other roles such as technologists and buyers have also been demonstrated to have an impact upon the creative process of incorporating sustainability within fashion product development. If the notion of creativity within the clothing industry can be applied to both manufacturing and thought processes involved in product development and production, rather than adhering to a narrower definition of creativity being restricted to aesthetic ideas devised by designers, this offers more scope for the incorporation of sustainable practices within the visual and practical 
creation of physical products. The incorporation of more sustainable practices within creative processes at work is becoming increasingly significant and in the future, regulations may be imposed which make a more sustainable approach towards creativity compulsory. The present notion that sustainable design is an innovative and therefore unusual phenomenon, is likely to give way to it becoming standard practice for future designers, due to increasing acknowledgement of the importance of minimising sustainability impacts.

The research in the case concludes that a lack of governance and agency, rather than a lack of creativity, inhibits technical capability to enhance clothing longevity. The research adds empirical, commercial data to theoretical work, drawing on diverse schools of thought. The findings emphasise the conflicts between creativity, commercial drivers and sustainability imperatives, product longevity and other approaches to sustainability, and the creative, technical and financial challenges implied by hybrid approaches to scale. The company mandate needs to address both commercial and sustainability drivers, reinforced with creative design and technical innovation, where a fundamental shift is required to give multifunctional design teams the capacity to utilise their creative skills and knowledge within a supportive, but global, business structure (Curwen et al. 2012).

Implications for managers are that key factors which foster creativity within a team (Eubanks et al. 2014) can be provided by supportive management to encourage creative and sustainable product innovation, such as autonomy, mentoring and networking, to encourage a supportive positive climate towards problem-solving for sustainable design issues via collaborative teamwork, both within organisations and with external stakeholders such as suppliers.

One of the key barriers to the wider adoption of practices to facilitate product longevity in the case was the lack of information available to educate both practitioners and consumers in this area and therefore providing that information to those engaged in product development, 
as referred to in the case, could enable them to add to their knowledge to devise creative solutions. Governmental strategies can impact upon the rapidity of implementing creative sustainable product development through policies and the distribution of publications to inform more sustainable practices. Sharing information on sustainable practices within the clothing longevity tool-kit can offer businesses the opportunity to benefit from the knowledge of members of a product sector which usually shuns collaboration with competitors and is notoriously secretive. Finally, there is potential for a new theoretical model of creativity in relation to sustainability to be developed that would be applicable to both academic and business fields. Future research could investigate ways in which sustainable approaches can be incorporated into creative thinking in relation to design and product or service development, to enhance understanding of the commercial cost-benefit equation and evaluate alternative business models which facilitate sustainable innovation. As this research is limited to the UK market, there is an opportunity to further explore issues beyond national scale.

\section{References}

Abra, J. (1997). The motive for creative work: An inquiry with speculations about sports and religion. Creskill, New Jersey: Hampton Press.

Baer, M. (2012). Putting creativity to work: The implementation of creative ideas in organizations. Academy of Management Journal, 55(5), 1102-1119.

Barker, C. (2005). Cultural studies: Theory and practice. London: Sage.

Berman, E.M. \& Kim, C.G. (2010). Creativity management in public organizations. Public Performance and Management Review, 33(4), 619-652.

Black, S. (2008). Eco-chic: The fashion paradox. London: Black Dog. 
Boström, M., Jönsson, A.M., Lockie, S., Mol, A., \& Oosterveer, P. (2015). Sustainable and responsible supply chain governance: Challenges and opportunities. Journal of Cleaner Production, 107, 1-7.

Brun, A. \& Castelli, C. (2008). Supply chain strategy in the fashion industry: Developing a portfolio model depending on product, retail and brand. International Journal of Production Economics, 116,169-181.

Caniato, F., Caridi, M., Crippa, L., \& Moretto, A. (2012). Environmental sustainability in fashion supply chains: An exploratory case based research, International Journal of Production Economics, 135(2), 659-670.

Clark, D. (2009). Crunching creativity: An attempt to measure creative employment. Creative Industries Journal, 2(3), 217-230.

Cooper, T. (ed.) (2010). Longer lasting products: Alternatives to the throwaway society. Farnham: Gower.

Cooper, T., Hill, H., Kininmonth, J., Townsend, K. \& Hughes, M. (2013). Design for longevity: Guidance on increasing the active life of clothing. Banbury: WRAP. Retrieved from: http://www.wrap.org.uk/sites/files/wrap/Design\%20for\%20Longevity\%20Report_0.pdf Cooper, T., Oxborrow, L., Claxton, S., Goworek, H., Hill, H. and McLaren, A. (2016). Strategies to improve design and testing for clothing longevity. A research report completed for the Department for Environment, Food and Rural Affairs (EV0553). Defra: London. Cox, G. (2005). Cox review of creativity in business. London: HM Treasury. Retrieved from: http://webarchive.nationalarchives.gov.uk/20080910135408/http://www.hmtreasury.gov.uk/independent_reviews/cox_review/coxreview_index.cfm) Cucuzzella, C. (2016). Creativity, sustainable design and risk management. Journal of Cleaner Production, 135, 1548-558. 
Curwen, L. G., Park, J. \& Sarkar, A. K. (2012). Challenges and solutions of sustainable apparel product development: A case study of Eileen Fisher. Clothing and Textiles Research Journal, 31(1), 32-47.

DCMS (2016). Creative industries economic estimates. London: Department for Culture, Media and Sport. Retrieved from:

https://www.gov.uk/government/uploads/system/uploads/attachment_data/file/523024/Creati ve_Industries_Economic_Estimates_January_2016_Updated_201605.pdf

Defra (2011). Sustainable clothing roadmap progress report, London: Defra. Retrieved from: https://www.gov.uk/government/uploads/system/uploads/attachment_data/file/69299/pb1346 1-clothing-actionplan-110518.pdf

Eubanks, D.L., Palanski, M.E., Iswart, J., Hammond, M.M. \& Oguntebi, J. (2014). Creativity in early and established career: Insights into multi-level drivers from Nobel Prize winners. The Journal of Creative Behavior, 50(4), 229-251.

Farrer, J. (2010). Remediation: Discussing fashion textiles sustainability. In Gwilt, A. \& Rissanen, T., (Eds.), Shaping sustainable fashion: Changing the way we make and use clothes (pp. 19-34). London: Earthscan.

Fletcher, K. (2007). Sustainable fashion and textiles: Design journeys. London: Earthscan. Fletcher, K. (2012). Durability, fashion, sustainability: The processes and practices of use. Fashion Practice, 4(2), 221-238.

Fletcher K. \& Grose, L. (2012). Fashion and sustainability: Design for change. London: Laurence King Publishing.

Foursightonline (2017). About Foursight. Retrieved from:

https://foursightonline.com/pages/about-foursight

Frost, P. J., and Egri, C. P. (1991). The political process of innovation. In L. L. Cummings \& B. M. Staw (Eds.) Research in Organizational Behavior, Volume 13 (pp. 229-295). Greenwich, CT: JAI.

Gale, C. \& Kaur, J. (2002). The textile book. Oxford: Berg. 
Gam, H., Cao, H., Farr, C., \& Heine, L. (2008). C2CAD: A sustainable apparel design and production model. International Journal of Clothing Science and Technology, 21(4), 166-179. Giddens, A. (1986). The constitution of society: Outline of the theory of structuration (2 ${ }^{\text {nd }}$ ed.). Cambridge: Polity Press.

Gilson, L.L. \& Shalley, C.E. (2004). A little creativity goes a long way: An examination of teams' engagement in creative processes. Journal of Management, 30, 453-470. Goworek, H. (2006). Careers in fashion and textiles. Oxford: Blackwell Publishing. Green, S. G., Welsh, M. A. \& Dehler, G. E. (2003). Advocacy, performance, and threshold influences on decisions to terminate new product development. Academy of Management Journal, 46, 419-434.

Grose, L. (2013) Wisdoms from the fashion trenches. In Torres, A.L. and Gardetti, M.A., (eds.), Sustainable fashion and textiles (pp. 376-392). Sheffield: Greenleaf Publishing. Goworek, H., Hiller, A., Fisher, T., Cooper, T. \& Woodward, S. (2013). Consumers' attitudes towards sustainable fashion. In Torres, A.L. and Gardetti, M.A., (eds.), Sustainable fashion and textiles (pp. 376-392). Sheffield: Greenleaf Publishing.

Gwilt, A. and Rissanen, T. (Eds.) (2010). Shaping sustainable fashion: Changing the way we make and use clothes. London: Earthscan.

Hjelmgrem, D., Salomonson, M. \& Ekström, K.M. (2015). Upcycling of pre-consumer waste: opportunities and barriers in the furniture and clothing industries. In Ekström, K.M. Waste Management and Sustainable Consumption: Reflections on Consumer Waste (pp.187-198). Abingdon: Routledge.

Hoejmose, S., Brammer, S. \& Millington, A. (2012). "Green" supply chain management: The role of trust and top management in B2B and B2C markets. Industrial Marketing Management, 41, 609-620.

Hong, P., Kwon, H.B., \& Roh, J. (2009). Implementation of strategic green orientation in supply chain: An empirical study of manufacturing firms. European Journal of Innovation Management, 12, 512-532. 
Isaksen, S.G., Kaufmann, A.H. \& Bakken, B.T. (2014). An examination of the personality constructs underlying dimensions of creative problem-solving style. The Journal of Creative Behavior, 50(4), 268-281.

Kirton, M.J. (1976). Adaptors and innovators: A description and measure. Journal of Applied Psychology. 61, 622-629.

Knox, M. (2017) Interview with Helen Goworek, $18^{\text {th }}$ June 2017 (unpublished).

Laitala, K., \& Klepp, I. G. (2011). Environmental improvement by prolonging clothing use period. Paper presented at Towards sustainability in the textile and fashion industry, NICE conference, Copenhagen, 26-27th April.

Lockett, H., Johnson, M., Bastl, M. \& Evans, S. (2011). Product service systems and supply network relationships: An exploratory case study, Journal of Manufacturing Technology Management, 22, 293-313.

Lozano, R., Carpenter, A. \& Huisingh, D. (2015). A review of 'theories of the firm' and their contributions to corporate sustainability. Journal of Cleaner Production, 106, 430-442. McKerracher, A. (2016). Understanding creativity, one metaphor at a time. Creativity Research Journal, 28(4), 417-425.

McLaren, A. \& McLauchlan, S. (2015). Crafting sustainable repairs: Practice-based approaches to extending the life of clothes. In Cooper, T., Braithwaite, N., Moreno, M. \& Salvia, G. (eds.), Product lifetimes and the environment (PLATE) conference proceedings, $17^{\text {th }}-19^{\text {th }}$ June 2015 (pp. 221-228). Nottingham: Nottingham Trent University: CADBE. McMahon, K., Ruggeri, A., Kämmer, J.E. \& Katsikopoulos, K.V. (2016). Beyond idea generation: The power of groups in developing ideas. Creativity Research Journal, 28(3), 247-257.

Mintel Oxygen (2011). Women's fashion lifestyles, May. London: Mintel. Mould, O., Vorley, T. \& Roodhouse, S. (2009). Realizing capabilities - Academic creativity and the creative industries. Creative Industries Journal, 1(2), 137-150.

Mumford, M.D. \& Gustafson, S.B. (1988). Creativity syndrome: Integration, application, and innovation. Psychological Bulletin, 103, 27-43. 
Niinimäki, K. \& Hassi, L. (2011). Emerging design strategies in sustainable production and consumption of textiles and clothing. Journal of Cleaner Production, 19, 1876-1883.

Niinimäki, K. (2012). Proactive fashion design for sustainable consumption. The Nordic Textile Journal, 1, 60-69.

Nogueira, S.E., Almeida, L., Garces, S., Pocinho, M. \& Wechsler, S. (2015). The style troika model: A structural model of the thinking and creating styles scale. The Journal of Creative Behavior, 50(4), 333-346.

Palomo-Lovinski, N. \& Hahn, K. (2014). Fashion design industry impressions of current sustainable practices. Journal of Fashion Practice, 6(1), 87-106.

Perkins, D.N. (1984). Creativity by design. Educational Leadership, 42, 18-25

Puryear, J.S. (2014). Inside the creative sifter: Recognizing metacognition in creativity development. The Journal of Creative Behavior, 50(4), 321-332.

Rogers, E. (1995). Diffusion of innovations. New York: Free Press.

Rogers, B. (1997). Creating product strategies. London: International Thomson Business Press.

Runco, M. A., \& Jaeger, G. J. (2012). The standard definition of creativity. Creativity Research Journal, 24(1), 92-96.

Sohn, S. Y. \& Jung, G. S. (2010). Effect of creativity on innovation: Do creativity initiatives have significant impact on innovative performance in Korean firms? Creativity Research Journal, 22, 320-328.

Spicer, A. (2006). Beyond the convergence-divergence debate: The role of spatial scales in transforming organizational logic. Organization Studies, 27(10), 1467-1483.

Streit, C.M. \& Davies, I.A. (2013). 'Sustainability isn't sexy’ An exploratory study into luxury fashion. In Torres, A.L. and Gardetti, M.A., (Eds.), Sustainable fashion and textiles (pp. 207222). Sheffield: Greenleaf Publishing. 
Taylor, D. (2013). Spray-on socks: Ethics, agency, and the design of product-service systems. Design Issues, 29(3), 52-63.

Treffinger, D.J., Selby, E.C., \& Isaksen, S.G. (2008). Understanding individual problemsolving style: A key to learning and applying creative problem-solving. Learning and Individual Differences, 18, 390-401.

Walker, R. (2006). Innovation type and diffusion: An empirical analysis of local government. Public Administration, 84(2), 311-335.

Walker, S. (2009). Designing sustainability. London: Routledge.

Wilson, N. (2009). Learning to manage creativity: An occupational hazard for the UK's creative industries. Creative Industries Journal, 2(2), 179-190.

WRAP (2012). Valuing our clothes: The true cost of how we design, use and dispose of clothing in the UK. Banbury: WRAP. Retrieved from:

http://www.wrap.org.uk/sites/files/wrap/VoC\%20FINAL\%20online\%202012\%2007\%2011.pdf WRAP (2013). Clothing longevity - Measuring active use. Banbury: WRAP. Retrieved from: http://www.wrap.org.uk/content/clothing-longevity-measuring-active-use WRAP (2014). Development of an industry protocol on clothing longevity. Banbury: WRAP. Retrieved from: http://www.wrap.org.uk/sites/files/wrap/Clothing\%20Longevity\%20Protocol_0.pdf 